\title{
Social innovation between necessity and opportunity
}

\author{
U. Berkis ${ }^{1,2}$, I. Ozolanta ${ }^{1,2}$, J. Vike ${ }^{1,2}$, and J. Blazarene ${ }^{2}$ \\ ${ }^{1}$ Rīga Stradiņš University, Riga, Latvia \\ ${ }^{2}$ Latvian Council of Science, Latvia
}

\begin{abstract}
The contribution of social innovation to the institutional change has been studied in the case of promoting healthy ageing. While major institutional change is well memorized by the present generation, the iterative approach to social innovation build up, and reaching the critical mass for a leap is viewed in the context of a specific region and social group. Selected types of social innovations are projected in their impact on societal challenges and institutional transformation potential.
\end{abstract}

\section{Introduction}

The transitional process in Central and Eastern Europe (CEE) during the 90-ies followed a pattern of a typical Northian - induced by major external shock - institutional change [1]. The relative straightforwardness of the transitional trajectory and societal consensus in reaching the major milestone - joining the European Union - contributed to exuberant optimism about sufficiency of preconditions for the system evolution towards a stable attractor. This was viewed as an achievement in evolutionary economics, a relatively new branch of science then desperately looking for evidence [5], and the happy revelation gave rise to specialized literature as Journal of Evolutionary Economics (1991). Later, it became evident that some of the most successful formerly centralized economies not necessarily were following orthodox free market models, literature started to cluster, for instance, with the establishment of the Journal of Evolutionary Economics and Social Complexity Science (2015). On the micro level remarkable impact was attributed to property rights and governance (corporate, public) and they largely determine the landscape of outcomes and major remaining challenges.

The Great Recession which started in Europe in 2008 produced in case of Latvia an external shock by intensity comparable with the 90 -ies. However, no major institutional change occurred yet. This is generally not a true proposition for all EU countries where strong centrifugal forces have institutionalized, but in Latvia the response to the external shock was muted in comparison to stimulus size. It was even called a "success story" and the enormous slump during 2009-2011 assumed to be just a deviation from the trend with a following imminent return to the long-term trajectory. An opinion proliferated widely that gradual social innovation can bring the same outcomes as a more profound institutional change. At the same time in Southern Europe the uncertainty persists regarding the sustainability of the trending trajectory. There has been considerable talk of "structural reforms" arising from political, but also financial industry circles, but not so much of common understanding which reforms are to be classified as "structural". 
The study will analyze the social innovation as an encouragement, promoter and satellite of institutional change. While there is now a strong support to the social innovation process in the EU with the establishment of the EaSI central programme [6], the principally unanswered question is - whether the social innovation can evolve into iterative process leading to larger institutional change as opposed to black swan events. Social cohesion promoted by directed social innovation, can lead to better health, educational and demographic outcomes, but also ignite the society as an activated medium where positive feedback can lead to major upswings.

\section{Institutional change then and now}

Compared to complete reorganization of their societies during the 90-ies, the period afterwards was rather scarce in institutional change in CEE. Societal alterations occurred in the frame of setups created during transition. Even if there was clearly demand for more leadership based societal model, the supply was limited and the governance rarely underwent major changes. On the causative side there are several clear determinants of the institutional dynamics just before and after the Great Recession:

1. Absence of further transformational plot. In the terminology of evolutionary theory, no clear attractor has emerged during the Recession. The prosperity of Germany relative to European background delivers no scripting impetus to smaller countries. This is not a CEE specific problem, so even in case of Finland the lack of common understanding about future script has very protracted nature, and the economy has poor record already for the $7^{\text {th }}$ year. During the Recession behavioral pattern protruded: if some remedy doesn't work, the solution is more of the same. While initially true for quantitative easing approach, at a later stage the aggravation involved various structural reforms and austerity;

2. Differential migration. Latvia and other CEE countries, especially those where the crisis onset was relatively early and powerful, initially profited from the outward migration as it radically lowered the unemployment bill. However, medium term effect is the enforced demographic ageing of CEE societies as the Young are much more mobile than the Old. The transformational capacity clearly diminishes, risk aversion increases in an ageing society more and more dependent on entitlements and benefits. The next milestone, according to the past experience, can be expected at a 10-15 years distance, which is not a real target for ageing societies plagued by poor healthcare services and decreasing incomes. Distortions of demographic pyramid reduce the ability of the working generation to survive substantial reforms in old age provision, as they have to pay for the Old according to the laws of the past, and in parallel make double payment for their own new scheme. Therefore the capitalized pension schemes in CEE suffered a blow during the Recession, with Poland and Hungary abandoning them entirely, Estonia and Latvia severely reducing contributions. In a highly volatile environment combined with low interest rates on secure deposits, capitalization of entitlements is questionable;

3. Loss of market discovery force. The intense monetary stimulus delivered by World central banks, has severely distorted the price discovery process, especially on the asset side. Banking industry has obtained the privilege to obtain resources for almost zero capital costs, whereas the access modalities for consumer and home loans have improved insignificantly. This is an important point, as it precludes loan uptake by elderly and makes limited the propensity for following generations to accept interest 
payments of their ancestors. More distant impact arises from very low deposit interest rates and extinction of the classical life insurance as a way of providing for old age.

4. Lack of precedence, weak theoretical reasoning and insufficient modeling of the processes. In case of Latvia this has been very immanent, as there has been no forecast and modeling preceding the Recession, the Latvian society was price taker for the events developing. Remarkable is the almost complete lack of discussion on TTIP in Latvia, which is in stark contrast with grim perspectives of still closed sectors which will be subject to opening under major free trade agreement, like healthcare.

In general, the conditions for an institutional change have been observed by several studies. One of the recent is by Cologne institute of economic research [1] which emphasizes the divergence between South and North of Europe. Latvia while located in geographical North, however, does not possess the accumulated capital stock and assets like northern EU Old member states, and should be classified as a catch-up country where internal adjustment forces are confronted with unfavorable external economic environment. The EU cohesion measures which are based on GDP/capita are not always a straightforward measure. Under the process of population decrease, there can be increase in the ratio despite of any reasonable economic growth. At the same time infrastructure does not possess proportional cost reduction effects, and smaller population has to sustain a larger stock of infrastructure.

Social innovation related to institutional change can be predecessor of innovative set of "rules of the game", a trial laboratory, or it can create environmental conditions for a plot to develop. Regarding the rapidly developing challenges to care and healthcare systems, we will consider the main forms of social innovation promoting active and healthy ageing, their potential to promote iterative changes in the institutions responsible for life-long social policies. While there can be more global approach like "Levensloopregeling" in the Netherlands, normally the institutional formation described here is of local/group nature.

\section{Time banks}

Time banks are relatively simple establishments based on the rule that able participants deliver their efforts to the benefit of participants in a disabled or restrained condition, and get their time credits stored in the time bank. Technically there are even standard computeraided solutions which can be used by the managing body.

While voluntary work is no innovation, time credits as surrogate money have several very specific innovative properties. Their validity to CEE social development is restricted.

They are based on relative permanence of the involved community. There have been efforts to establish time banks with transferability and wider coverage area, but this could be rather a case for very mature setups. Differential migration and still ongoing economic transformation in the rural communities restrict the supply and reduce the operational simplicity. In a city environment security reasons can add to the operational difficulties. The scheme can work better where there is a larger number of younger Old, capable of delivering services to older Old. Intergenerational impact in CEE will be limited by differential migration and demographic tree specifics.

Nonetheless, time banks have also a positive perspective, as they show a successful innovative alternative to excessive monetization of social services. Monetization is a consequence of the exuberance in transitional processes of the 90-ies where direct establishment of market mechanisms was not feasible. The main mechanism of introduction of the market institutions relied on price liberation and empowerment of the price setting, 
together with abandonment of subsidies. This was relatively artificial way of market mechanism establishment, which was incompatible with non-monetary turnover of services. At the end of 90-ies there started to appear doubts about sustainability of market based delivery of social services; this coincided with decrease of available workforce pool.

Time banks can have positive perspective as the digitalization and automation will free up more of the time of the workforce previously occupied by routine jobs. It depends on how the societies will react to the scarcity of work in the "New World of Work". Reduction in the working time will open substantial resources for time banking benefiting ageing populations.

Another stimulus for the development of time banks is the low interest rate regime for classical financial industry. Low interest regiment arising from deflationary economic environment substantially reduces the saving propensity. For instance, savings of 1 million EUR could generate 40-50.000 returns in the high-interest mode before the Recession. Now in the environment where $0,07 \%$ is the maximum retail deposit rate (July 2015, Latvia), it could return 700 EUR/year. This is completely insufficient and will lead to rapid consumption of the capital. Failure of classical old-age savings promotes re-innovation: during the interbellum period the credit unions played an important role in Latvia with their model of classical deposits on one side and investment into equity on the other side. Recently, credit unions undergo reactivation in local communities as well as in homogenous employee groups. They are further strengthened by low performance of the pension funds affected by high stock market volatility.

\section{Community relationship capitalisation based social innovation}

Community based social services have long shadow from the former "combines", characteristic to CEE large enterprises, but also for established large companies in Western Europe. There is pressure to separate from former "carrying for all" enterprise as part of "structural reform", towards "paying for all" neoliberal start-up. The tendency to restore convexity in market-based models is very typical for the nought paradigms; more practical consequence is the expulsion of benefits, entitlements and direct support from firm's cost structures, as they are supposed to result in flat indifference lines or multiple equilibrium. While the costs unrelated to production processes are small by their structure, they severely distort the neoclassical models, and if abandonment is not possible, transformation into taxlike charges as in case of employer-based pension insurance is preferable, as it does not distort the convexity assumptions.

Intergenerational aspect is very integral to community based interaction. The main action lines are increasing the mobility of elderly, slowing of mental impairment via mental tasks like aiding younger in their homework at school, and also learning from the young, for instance, the use of IT and mobile technologies. Communities where valuable information is capitalized and the formation of social capital has a strong foundation, like ageing cafes, discussion circles of elderly, discussion platforms for informal carers provide important feedback to stakeholders and decision makers.

\section{Package based social innovation}

The ageing in the home environment has created demand for mobile service delivery and packages of aid. While costs associated with various alarm and care provision schemes can be high, the indirect effects as the promotion of consumption versus saving behavior can have positive impact for the wider society. If the packages are supported by adequate insurance schemes, this can create a new wave of demand in grey economy, so desperately needed in the demand-starving Eurozone. 
The threats to packages can arise directly from structural reforms. One of detrimental effects of structural reforms is the decomposition of insurance and other solidarity based schemes into cost determinants. In Baltic countries there has been no dynamics in the insurance market for long-term care, and any increases of spending will be projected to strained social care budgets. The rather low social support to carers creates saving pressure on the ageing generation and their relatives. More equitable risk sharing is necessary to improve overall societal resilience to major shocks. The anticipation of next global shock in the business cycle prefers short period of investment return which is not compatible with inefficient risk sharing models.

\section{Digitalization and social innovation}

In the European perspective Nordic countries are in the avant-garde of development of the digital services, internet of things benefitting the population of elderly. Causative factor is the better technological advancement, but even more the geographical population sparseness. Similarities are observable in Baltic countries; but also dissimilarities - the model of monocentric gravitational development is very strong in Latvia with the Capital city metropolitan region generating around $70 \%$ of national income.

IT literacy and interaction for the new digitalization era balances between improving human-computer interfaces and neuro-degeneration as an ageing consequence on the restrictive side. IT technologies have been major source of asset market volatility, and IT literacy can be an important source of social expulsion. Vanishing network of banking services in rural Latvia becomes an important impediment to ageing environments outside of the major industrial centres. While everyday financial transactions can be accomplished in virtual space, access to more complex financial products can be greatly impaired for dispersed populations.

Behaviouristic aspects, marketing pressure on the elderly have increasing penetration depth accompanying development of digital environments. Background daemons registering every mouse activity, automated analysis of preferences create a fertile medium for economic exploitation of greying population. Intelligent protection of vulnerable populations can occur only as state aided research outcome, as large companies are not interested to develop it. Security, privacy and free choice of goods and services are not guaranteed in the digitalization era.

\section{Conclusions}

The development of social services in a catch-up economy in a deflationary economic environment as in case of Latvia requires innovative analysis and modelling framework. The $20+$ years old monetization paradigm has reached its limits. Future scenarios depend on switching events, like mass immigration inflow and on medium-term effects like differential migration and on long-term determinants like healthcare cost projections.

A major milestone for life-long social policy environment will be the TTIP (Transatlantic Trade and Investment Partnership). While education and research are greatly shielded from effects of a major free trade agreement, healthcare and long-term care services are fully subjected to the opening. The effects of further monetization, compulsory procurement and equal access to state aid are yet insufficiently modelled in the recent socio-economic research.

Social innovation promoting healthy ageing shows significant resilience to Baumol's cost disease affecting social and health care. By circumventing excessive cost calculations and involving synergies and implicit benefits, social innovation can demonstrate admirable complement to traditional economic activity. 
The paper has been developed collaborating in the FP7 INNOVAGE project No. 306058. http://www. innovage.group. shef .ac.uk/. Research activity supported by Latvian National Research programme EKOSOC-LV.

\section{innovAge}

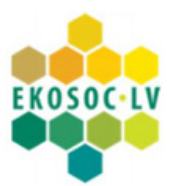

\section{References}

[1] Empirical Studies in Institutional Change. Ed. Lee J. Alston, Thrainn Eggertsson, Douglas North. Cambridge University press, $376 \mathrm{p}$.

[2] http://www.welt.de/wirtschaft/article144444056/Suedeuropaeerverlieren-den-Glauben-an-Demokratie.html

[3] Grèce : Mélenchon parle de l'Allemagne nazie pour dénoncer l'inflexibilité de Merkel. Libération 13.07.2015.

[4] Colas N. "Behavioral and Evolutionary Economics: The Search to Better Understand Economic Decisions" 29.07.2015 http://www.convergex.com/the-share/ behavioral-and-evolutionary-economics-the-search-to-betterunderstand-econo

[5] Murrell P. Evolutionary and radical approaches to economic reform. Economics of Planning 25(1):79-95, 1992.

[6] ec.europa.eu/social/easi

[7] S. Tarkoma, H. Ailisto. The internet of things program: The finnish perspective.IEEE Communications Magazine, 51(3), art. no. 6476854, pp. 10-11 (2013).

[8] G. Naegele. Soziale lebenslaufpolitik. Verlag für Sozialwissenschaften. Wiesbaden, 2010, 617 p. 